\section{Stress and coping strategies in the emergency room}

\author{
Paola lannello, Stefania Balzarotti \\ Department of Psychology, Catholic \\ University of the Sacred Heart, Milan, \\ Italy
}

\begin{abstract}
The main goal of the present study was to examine how levels of perceived stress reported by emergency physicians vary depending on the type of coping style. Seventy physicians working in four emergency departments in Northern Italy were administered two questionnaires measuring perceived levels of work related stress and habitual use of different coping styles. Results show that emergency physicians reported to rely on task-oriented coping more than on emotion-oriented and avoidance-oriented coping. Furthermore, coping styles were significant predictors of perceived stress. Specifically, after controlling for age and gender, task- and avoidance-oriented coping styles were predictors of less work related stress, while emotion-oriented coping was associated with higher levels of stress. The implications are discussed.
\end{abstract}

\section{Introduction}

The emotions experienced in the workplace as well as their regulation to make them in line with job requirements are a relevant area of interest and research. ${ }^{1,2}$ The so-called emotional labour $^{3}$ has been defined as the effort involved when employees regulate their emotional display in an attempt to meet organizationally based expectations specific to their roles. ${ }^{4}$ Organizationally based expectations or norms define which emotions employees should express and which emotions they should not express. To the extent that felt emotions (e.g., anger, frustration, sadness) conflict with context-desired ones, employees may perceive dissonance, and thus try to regulate their feelings in order to exhibit job congruent emotions. ${ }^{5}$

The ability to regulate emotional responses is thought to impact on perceived quality of working life, on workers' psychological wellbeing as well as on their performance. ${ }^{6}$ This may be especially true within the context of service organizations (such as hospitals) which involve employee-customer interactions, with the emotions experienced by the employees influencing their face-to-face interactions with customers, and thus the quality of the service offered. ${ }^{3}$ In addition, healthcare professionals such as nurses and physicians are daily confronted with events involving others' (i.e., patients' and relatives') suffering, which are likely to generate highly negative and stressful emotions. The failure to successfully down-regulate negative emotions is a key risk factor for burnout, ${ }^{7}$ which is defined by emotional exhaustion, depersonalization and a low sense of personal work accomplishment. ${ }^{8,9}$ Burnout is the result of chronic occupational stress, and its main consequences are reduced levels of work performance and desire to leave the job. Recent studies have shown that healthcare workers' coping strategies may be a risk or protective factor for the development of distress and emotional problems. ${ }^{10}$

Psychological studies have examined the strategies individuals generally use to cope with stressful events. Within this body of literature, coping ${ }^{11}$ has been defined as a multidimensional process that comprises both cognitive and behavioral efforts to manage external and/or internal demands that are evaluated as taxing or exceeding the individual's resources. ${ }^{12}$ The term thus comprises all conscious and unconscious mechanisms by means of which people deal with stressors. ${ }^{13}$ For instance, one may directly act on the stressor (e.g., taking instrumental action, trying to solve the problem, planning what to do), reinterpret the meaning of the event (e.g., thinking that the situation has its positive sides), seek social support (e.g., asking a friend for help), avoid the problem (e.g., thinking about positive things that have nothing to do with it, or turning to leisure-time activities). Some coping strategies (e.g., positive reinterpretation, problem solving, goal setting) are generally thought to be more adaptive than others (e.g., denial, self-blame, rumination).

Coping styles or strategies are commonly conceived and measured as stable, dispositional traits characterising individual's personality. ${ }^{14}$ Along these lines, Bolger ${ }^{15}$ has defined coping as personality in action under stress. For this reason, coping has been mainly investigated by using self-report questionnaires to measure and assess how individuals differ in their habitual use of coping behaviors and strategies. ${ }^{16,17}$ However, it has also been pointed out that the efficacy of coping strategies may also depend on the type of stressor. ${ }^{18}$ For instance, stress may be caused by work and employment concerns (e.g., excessive job demands, a job interview, conflict with coworkers or supervisors, job insecurity, etc.) or by personal concerns (e.g., sleep problems, injury or illness, separation/divorce, the death of a family member, money problems, conflicts in interpersonal relationships, etc.). These stressors may be short- or long-term, as well as more or less controllable. For this reason, theorists have argued that the individuals should
Correspondence: Paola Iannello, Department of Psychology, Catholic University of the Sacred Heart, Largo Gemelli 1, 20123 Milan, Italy.

Tel. +39.02.7234.2284 - Fax: +39-02-7234.2280

E-mail:paola.iannello@unicatt.it

Key words: stress, coping styles, emergency room.

Received for publication: 15 April 2014.

Revision received: 18 June 2014

Accepted for publication: 30 June 2014.

This work is licensed under a Creative Commons Attribution 3.0 License (by-nc 3.0).

(C) Copyright P. Iannello and S. Balzarotti et al., 2014 Licensee PAGEPress, Italy

Emergency Care Journal 2014; 10:3788

doi:10.4081/ecj.2014.3788

be able to adapt their coping behavior to the situation, thus relying on a number of different strategies rather than on the repetitive use of a few ones..$^{19}$ When the stressor is perceived by the individuals as outside their coping abilities, he or she will experience distress (or negative stress), which involves anxiety and reduced performance, and may lead to mental or physical problems. ${ }^{11,20}$

Although existing measures of coping draw from different theoretical models, three main coping dimensions are almost universally acknowledged: i) problem- $v s$ emotion-focused coping; ii) engagement $v s$ disengagement (or avoidance); and ii) primary vs secondary coping..$^{21,22,14}$ Modern coping research began with the distinction between problem-focused coping, ${ }^{12}$ which includes all the attempts to directly influence the source of stress (e.g., instrumental action, problem solving, planning), and emotion-focused coping, intended to minimize negative emotions through strategies such as venting and rumination (i.e., the individual acts not so much to change the situation, but to down-regulate his or her negative feelings such as anxiety and worry). Recently, Stanton and colleagues ${ }^{23,24}$ pointed out that emotionfocused coping has been defined in ways that include strategies as diverse as relaxation, rumination, seeking social support, including negative emotional expression items (e.g., I become very tense). These authors have argued that most questionnaires measuring emotionfocused coping ${ }^{17}$ assess strategies that involve unregulated emotional reactivity (e.g., venting), rather than forms of coping through which the individual is able to appropriately express and modulate his or her feelings (e.g., active attempts to acknowledge and understand emotions).

The engagement-disengagement distinction concerns orientation towards or away from stress, with the engagement coping (e.g., 
problem solving, taking control) involving active attempts to deal with a situation or associated emotions, and disengagement coping (e.g., distancing, denial) involving distancing the stressor or related feelings. ${ }^{14}$ Finally, the distinction between primary and secondary coping focuses on coping goals, with primary coping intended to change the source of stress or associated emotions, and secondary coping used to adapt to the situation (e.g., when it is not possible to change it) through strategies such as reinterpretation, acceptance, and humour. Although coping strategies are not universally beneficial or dysfunctional, problem focused coping, engagement, primary and secondary coping have been generally found to predict better physical and mental health, while disengagement and emotion-coping have been found to predict maladaptive outcomes. ${ }^{21}$

Several studies have examined psychological stress as perceived by physicians from various medical specialities. ${ }^{25-29}$ By contrast, little research has examined which coping strategies physicians habitually use to face stressful situations. ${ }^{30-32}$ These studies have most often used a qualitative, bottom-up approach (e.g., interviews) to identify the coping strategies most frequently reported by physicians to deal with work related stress, finding that physicians report to often use practices such as leisure-time activities, cultivation of relations with family and friends, self-demarcation with patients, active engagement, personal reflection and goal setting. ${ }^{32}$

The present study has two main goals. First, to determine the levels of work related stress as perceived by emergency physicians, as well as to assess the coping styles that they habitually use to cope with stressful situations. Second, to examine the association between perceived stress and physicians' coping styles, testing whether the type of coping style influences their perception of work related stress.

\section{Materials and Methods}

\section{Participants and procedure}

Seventy physicians (41 males and 29 females, mean age $=40.84$ years, $\mathrm{SD}=7.76$ ) working in the emergency departments of four hospitals in Northern Italy participated to the study. The sample comprised 49 physicians with $<10$ years' experience ( 24 males and 25 females) and 21 physicians with $>10$ years' experience (17 males and 4 females).

After obtaining the authorization from the directors of the emergency departments, the emergency physicians working in each department were contacted individually and explained the purpose of the study. The physicians who voluntarily accepted to take part in the research were then asked to fill in the questionnaires. Anonymity was guaranteed.

\section{Materials}

Coping Inventory for Stressful Situations (CISS). ${ }^{17}$ The Italian adaptation of Coping Inventory for Stressful Situations by Pedrabissi and Santinello ${ }^{33}$ was used. The CISS consists of 48 items assessing three styles of coping (16 items each): TaskOriented coping (e.g., focusing on the problem or analysing the problem; $\alpha=0.87$ ), EmotionOriented coping (e.g., feeling tense or angry; $\alpha=0.88$ ), and Avoidance-Oriented coping (e.g., turning to leisure-time activities or seeking social support; $\alpha=0.83$ ).

Job Stress Questionnaire (JSQ) ${ }^{34}$ In the present study, we employed the Italian adaptation of the revised questionnaire ${ }^{34}$ originally developed by Caplan and colleagues. ${ }^{35}$ The questionnaire $(\alpha=0.76)$ consists of 10 items asking the respondent to report levels of perceived stress associated with Workload (amount of work and time pressures), Role Conflict (having logically incompatible demands made by co-workers or supervisors), Role Ambiguity (inadequate information to perform ones' role in the organization), and Utilization of Skills (under-utilization of previously acquired skills in carrying out tasks required on the job).

\section{Results}

\section{Levels of perceived stress}

The mean level of stress perceived by the total sample was 2.69 ( $\mathrm{SD}=0.67)$. Examining the scores on each of the ten items of the questionnaire, three potential sources of perceived stress emerged as particularly critical: time pressure, lack of positive feedback when good results are obtained, and work demands interfering with personal life.

The perception of work related stress seemed to be influenced by gender [F (1.69) $=3.123, \mathrm{P}<0.05$ ], with women reporting higher levels of stress $(\mathrm{M}=2.85, \mathrm{SD}=0.75)$ than men $(\mathrm{M}=2.57, \mathrm{SD}=0.58)$. By contrast, no significant differences were found between physicians with $<10$ years' work experience and physicians with longer work experience [F $(1.69)=0.311, \mathrm{P}=0.579]$.

\section{Coping styles}

Emergency physicians reported to use taskoriented coping $(\mathrm{M}=62.72, \mathrm{SD}=7.97)$ more often than emotion-oriented ( $M=35.95$, $\mathrm{SD}=10.90)$ and avoidance-oriented coping $[\mathrm{M}=39.16, \quad \mathrm{SD}=9.72 ; \quad \mathrm{F}(2.139)=151.10 ;$ $\mathrm{P}<0.001]$. No significant differences emerged in task-oriented and emotion-oriented coping depending on either gender or work experience. However, work experience influenced avoidance-oriented coping: physicians with $<10$ years' experience tended to rely on avoidance coping more than physicians with $>10$ years' experience [ $\mathrm{F}(1.67)=7.08 ; \mathrm{P}<0.010]$.

\section{Correlations between work related stress and coping styles}

Pearson's two-tailed correlations are shown in Table 1. Results indicate that levels of perceived stress are positively associated with task-oriented coping and negatively associated with emotion-oriented coping. No significant correlation was found between perceived stress and avoidance-oriented coping. When considering the relationships among the three coping styles, emotion-oriented coping was positively associated with avoidance-oriented coping and negatively associated with task-oriented coping.

\section{The influence of coping styles on levels of perceived stress}

A linear regression analysis was performed to examine whether coping styles are significant predictors of perceived stress after controlling for physicians' age and gender. The regression model was statistically significant $\left[\mathrm{R}^{2}=0.35 ; \quad\right.$ F $\left.\quad(5,62)=6.56 ; \quad \mathrm{P}<0.001\right]$. Regression weights are displayed in Table 2. Results show that emotion-oriented coping is a significant predictor of higher perceived stress, while task- and avoidance-oriented coping are significant predictors of lower stress. These associations are not influenced by either age or gender.

Table 1. Pearson's two-tailed correlations between level of stress and coping styles.

\begin{tabular}{lcccc} 
& 1 & 2 & 3 & 4 \\
1 & - & & & \\
2 & $-0.363^{* *}$ & - & & \\
\hline 3 & $0.454^{* *}$ & $-0.409 * *$ & - & - \\
4 & -0.154 & -0.014 & $0.241^{*}$ & -
\end{tabular}




\section{Discussion}

Previous research has shown that many potential stressors are part of emergency physicians' workplace environment, such as organizational demands (e.g., long and tiring working hours, shift work, overcrowding of emergency departments), lack of gratification, imbalance between work and family. ${ }^{25}$ Also, emergency physicians often need to deal with different kinds of problems (e.g., types of disease) and make quick decisions in life-anddeath situations. Consistent with previous research, we found that time pressures, lack of positive feedback and work demands interfering with personal life were reported by our sample as the main sources of perceived work related stress. Also, similarly to previous studies, ${ }^{36}$ our findings show that socio-demographic factors such as gender influence perceived stress, with females reporting higher levels of stress than males.

Consistent with prior research assessing physicians' self-reported coping strategies, ${ }^{30}$ the present study suggests that, on average, emergency physicians rely on task-oriented coping (e.g., problem solving, active coping, planning) more often than on emotion-oriented and avoidance-oriented coping to deal with stressful events. Notably, avoidance-oriented coping was the only coping style to be influenced by work experience, with physicians with longer experience reporting to use this form of coping less frequently than younger physicians.

When examining the relationship between coping styles and work related stress - controlling for socio-demographic variables such as gender and age - our results show that task-oriented coping is a predictor of lower work related stress, while emotion-oriented coping is a predictor of higher levels of perceived stress, which is consistent with psychological literature on coping. ${ }^{12,22}$ Task-oriented coping is generally conceived as an adaptive form of coping: direct action on the source of stress may be linked to the feeling that one is able to master the situation and keep events under control. By contrast, emotion-oriented

Table 2. Regression analysis: influence of task-, emotion- and avoidance-oriented coping styles on perceived stress.

\begin{tabular}{lccc} 
Predictor & B & $\mathrm{t}$ & $\mathrm{P}$ \\
Socio-demographic variables & & & \\
$\quad$ Age & -0.05 & -0.45 & 0.65 \\
$\quad$ Gender & 0.19 & 1.71 & 0.09 \\
Coping styles & & & \\
$\quad$ Task-oriented coping & -0.23 & -1.99 & $<0.05$ \\
Emotion-oriented coping & 0.39 & 3.24 & $<0.001$ \\
Avoidance-oriented coping & -0.30 & -2.79 & $<0.05$ \\
\hline
\end{tabular}

coping comprises all the efforts to reduce inner negative feelings (e.g., anxiety, discomfort, etc.). In this study, emotion-oriented coping ${ }^{17}$ was assessed to include strategies that involve unregulated emotional reactivity $(e . g$., I feel anxious about not being able to cope, I become very tense), self-blame (e.g., I focus on my general inadequacies, I blame myself for being too emotional about this situation), and wishful thinking (e.g., I wish that I could change what had happened or how I felt). This may explain why physicians using this coping style are more likely to report high levels of stress. $^{23,24}$

An unexpected result concerned avoidanceoriented coping, which is generally conceived as a dysfunctional form of coping. ${ }^{22}$ Although the correlation between avoidance and perceived stress was not significant, avoidanceoriented coping was a significant predictor of lower stress in the regression model. There are three possible explanations for this result. First, the avoidance-oriented subscale used in this study ${ }^{17}$ assesses two types of strategies, that is, distraction (e.g., I go to a party, I go for a walk) and social diversion (e.g., I visit a fried, I try to be with other people), rather than more dysfunctional strategies such as denial (i.e., acting as nothing has happened) and behavioral disengagement (e.g., give up, quit trying to solve the problem). Second, prior studies examining physicians' coping strategies $^{30}$ have found that strategies related to distraction (e.g., turning to leisure-time activities, take a time out, spending time with family) are related to lower frequency of emotional exhaustion. Time away from work, switching of mentally and leisure activities may allow recovery of resources and energy, thus resulting in positive benefits for workers. Third, avoidance-related coping may be related to less perceived stress in the short-term (as measured in this study), but may have detrimental long-term effects on physicians' well-being. Future studies employing a longitudinal design are needed to better understand the mechanisms by which avoidance strategies are linked to stress perception among physicians.

[Emergency Care Journal 2014; 10:3788]

\section{Conclusions}

In sum, the present study suggests that the coping strategies emergency physicians habitually use to deal with stressors are important predictors of the levels of stress that they perceive at the workplace. Specifically, habitual use of task-oriented and avoidance-oriented coping emerges as beneficial to reduce stress levels, while emotion-oriented coping is associated with higher levels of work related stress. These results may be useful in developing programs to promote physicians' resilience and emotion regulation ability.

\section{References}

1. Ashkanasy NM, Hartel CEJ, Zerbe WJ. Emotions in the work place: research, theory, and practice. Westport, CT, USA: Quorum Books; 2000.

2. Fisher CD, Ashknasy NM. The emerging role of emotions in work life: an introduction. J Organ Behav 2000;21:123-9.

3. Hochschild A. The managed heart: commercialization of human feeling. Berkeley, CA, USA: University of California Press; 1983.

4. Brotheridge CM, Lee R. On the dimensionality of emotional labour: development and validation of an emotional labour scale. Paper presented at the First Conference on Emotions in Organizational Life, San Diego, CA, USA; 1998.

5. Zammuner VL, Lotto L, Galli C. Regulating emotions in the helping professions: nature, antecedents and consequences. Adv Mental Health 2003;2:213.

6. Smith P. The emotional labour of nursing. Basingstoke, UK: Macmillan; 1992.

7. Maslach C, Jackson S. Maslach burnout inventory. Firenze: Giunti Organizzazioni Speciali; 1993.

8. Dorz S, Novara C, Sica C, Sanavio E. La sindrome del burnout in operatori sanitari a contatto con malati di AIDS: variabili predittive. G Ital Med Lav Erg 2004;26:114-8.

9. Grassi L, Magnani K. Psychiatric morbidity and burnout in the medical profession: an Italian study of general practitioners and hospital physicians. Psychother Psychosom 2000;69:329-34.

10. Dorz S, Novara C, Sica C, Sanavio E. Predicting burnout among HIV/AIDS and oncology health care workers. Psychology and Health 2003;18:677-84.

11. Lazarus RS. Psychological stress and the coping process. New York, NY, USA: 
McGraw Hill; 1966.

12. Lazarus RS, Folkman S. Stress appraisal and coping. New York, NY, USA: Springer; 1984.

13. Sica C, Novara C, Dorz S, Sanavio E. Coping strategies: evidence for crosscultural differences? A preliminary study with the Italian version of Coping Orientations to Problems Experienced (COPE). Pers Indiv Differ 1997;23:10259.

14. Connor-Smith JK, Flachsbart C. Relations between personality and coping: a meta-analysis. J Pers Soc Psychol 2007;93:1080-107.

15. Bolger, N. Coping as a personality process. A prospective study. J Pers Soc Psychol 1990;59:525-37.

16. Folkman S, Lazarus RS. An analysis of coping in a middle-aged community sample. J Health Soc Behav 1980;21:21939.

17. Endler NS, Parker JDA. Multidimensional assessment of coping: a critical evaluation. J Pers Soc Psychol 1990;58:844-54.

18. Folkman S, Moskowitz JT. Coping: pitfalls and promise. Annu Rev Psychol 2004;55:745-74.

19. Lester N, Smart L, Baum A. Measuring coping flexibility. Psychol Health 1994;9:409-24.

20. Selye H. Stress without distress. Philadelphia, PA, USA: J.B. Lippincott Company; 1974.

21. Compas BE, Connor-Smith JK, Saltzman $\mathrm{H}$, et al. Coping with stress during childhood and adolescence: progress, prob- lems, and potential in theory and research. Psychol Bull 2001;127:87-127.

22. Skinner EA, Edge K, Altman J, Sherwood $\mathrm{H}$. Searching for the structure of coping: a review and critique of category systems for classifying ways of coping. Psychol Bull 2003;129:216-69.

23. Stanton AL, Danoff-Burg S, Cameron CL, Ellis AP. Coping through emotional approach: problems of conceptualization and confounding. J Pers Soc Psychol 1994;66:350-62.

24. Stanton AL, Kirk SB, Cameron CL, Danoff-Burg S. Coping through emotional approach: scale construction and validation. J Pers Soc Psychol 2000;78: 1150-69.

25. Balch CM, Freischlag JA, Shanafelt TD. Stress and burnout among surgeons: understanding and managing the syndrome and avoiding the adverse consequences. Arch Surg Chicago 2009;144:371-6.

26. Braun M, Schonfeldt-Lecuona C, Freudenmann R, Beschoner P. Burnout, depression and substance abuse in physicians. An overview of actual data in Germany. PsychoNeuro 2007;33:19-22.

27. Dyrbye LN, Thomas MR, Shanafelt TD. Systematic review of depression, anxiety, and other indicators of psychological distress among US and Canadian medical students. Acad Med 2006;81:354-73.

28. Goebert D, Thompson D, Takeshita J. Depressive symptoms in medical students and residents: a multi-school study. Acad Med 2009;84:236-41.

29. Schernhammer ES, Colditz GA. Suicide rates among physicians: a quantitative and gender assessment (meta-analysis). Am J Psychiat 2004;161:2295-302.

30. Lamaire JB, Wallace JE. Not all coping strategies are created equal: a mixed methods study exploring physicians' self-reported coping strategies. BMC Health Serv Res 2010;10:208.

31. Stevenson AD, Phillips CB, Anderson KJ. Resilience among doctors who work in challenging areas: a qualitative study. Brit J Gen Pract 2011;61:404-10.

32. Zwack J, Schweitzer J. If every fifth physician is affected by burnout, what about the other four? Resilience strategies of experienced physicians. Acad Med 2013;88:382-9.

33. Pedrabissi L, Santinello M. Coping inventory for stressful situations: revision of validity and psychometric properties. Ricerche di Psicologia 1994;18:4963.

34. Harris JA, Saltstone R, Fraboni M. An evaluation of the job stress questionnaire with a sample of entrepreneurs. J Bus Psychol 1999;13:447-55.

35. Caplan R, Cobb S, French J, et al. Demands and worker health: main effects and organizational differences. Washington, DC: US Government Printing Office; 1975.

36. Isikhan V, Comez T, Zafer Danis M. Job stress and coping strategies in health care professionals working with cancer patients. Eur J Oncol Nurs 2004;8:23444. 